УДК $141,165.6 / 8$

DOI: $10.18101 / 1994-0866-2019-1-45-53$

\title{
К ФИЛОСОФСКОЙ КОНЦЕПЦИИ ДИАЛОГА (ОТ М. БУБЕРА К В. С. БИБЛЕРУ)
}

\author{
(C) Корягина Татьяна Олеговна \\ аспирант, \\ Забайкальский государственный университет \\ 672000, Россия, г. Чита, ул. Александро-Заводская, 30 \\ E-mail: kitay_koriagina@bk.ru
}

В статье рассматривается диалог как философская концепция, имеющая ряд характерных особенностей и черт. Диалог как основная форма устного или письменного высказывания между двумя или более участниками беседы трансформируется в диалог культурный, который находится в авангарде диалогических отношений человека с многообразными формами бытия. В центре исследования раскрывается интерпретация концепции диалога в идеях видных мыслителей, таких как М. Бубер, М. М. Бахтин и В. С. Библер. Автор, апеллируя к научным трудам вышеуказанных исследователей, эксплицирует главные отличительные черты диалога. Основной особенностью диалога является направленность на обмен знаниями между двумя или более партнерами, отношения которых закреплены на предметном или духовном уровне. С помощью исторического и концептуального методов осуществлен общий анализ диалога и диалогических отношений «Я-Ты» и «Я-Оно» (М. Бубер), «Я» с Другим (М. М. Бахтин) и «Я-Ты» (В. С. Библер), а также диалога культур в рамках исследовательской деятельности М. М. Бахтина и В. С. Библера. Полученные исследования представляют теоретическую основу концептуальных особенностей диалога в рамках философской традиции. Накопленный материал в области диалога может служить фундаментом для дальнейшего поиска и анализа характерных особенностей и ключевых принципов диалогизма.

Ключевые слова: диалог; «Я-Ты»; «Я-Оно»; «Я» с Другим; диалог культур; диалогические отношения; диалогика.

Для цитирования:

Корягина Т. О. К философской концепции диалога (от М. Бубера к В. С. Библеру) // Вестник Бурятского государственного университета. Философия. 2019. Вып. 1. C. $45-53$.

Диалогическая природа заключена в каждом акте человеческой деятельности, в каждом культурном явлении, которые благодаря взаимодополняемости и взаимососуществованию образуют общую картину мира. Полученное от прошлых эпох наследие является продуктом установления диалогических отношений человека с формами бытия на уровне духовного мира и эмпирического опыта индивида. В процессе индивидуального становления человек как личность стремится познать мир через призму диалога и диалогического мировосприятия. Следовательно, диалог играет роль коррелята между различными социальными и культурными институтами, выполняет функцию связующего звена между человеком и вещами, человеком и духовными сущностями и создает каркас для последующего взаимодействия индивида с бытием.

Целью настоящего исследования является определение предметного поля проблематики диалога, а также анализ теоретических аспектов диалога, которые направлены на последующее выявление научных предпосылок в изучении дан- 
ного вопроса. Основная задача научной работы заключается в исследовании общих ключевых принципов концепции диалога, отправной точкой для которых являются работы известных философов ХХ в., таких как М. Бубер, М. М. Бахтин, В. С. Библер. Материалы научно-теоретической статьи могут быть использованы в учебно-педагогической теории для чтения лекций по философской антропологии, социальной философии, культурологии, а также при составлении учебников и пособий для студентов и слушателей.

Диалог начиная с античности находится в центре внимания философов. Диалоги Платона и других философов античной культуры заложили основную базу для интерпретации диалога как одного из видов словесного изображения, особой формы устной речи на заданную тему двух или более участников. Далее понятие диалога, претерпевая значительные изменения, приобретает философский характер. Современное понятие диалога четко представлено в трудах западной и отечественной философии. Представителями западной философии диалога принято считать М. Бубера, М. Хайдеггера, Г. Гадамера. Среди крупных отечественных мыслителей, занимавшихся исследованием диалога, следует отметить М. М. Бахтина, Э. В. Ильенкова, В. С. Библера, М. К. Мамардашвили.

Методология данного исследования включает концептуальный анализ, предполагающий выявление концептов в научной деятельности ученых, направленный на рассмотрение и изучение диалога, а также исторический анализ, благодаря которому удастся проследить генезис и трансформацию диалога с культурных и философских позиций. Данные методы способствуют решению проблем настоящего исследования, связанных с пониманием концептуальной модели, исторических парадигм диалога, нетождественных концептуальных признаков, которые находятся на стыке междисциплинарных границ философии и культурологии.

Мартин Бубер (1878-1965), экзистенциальный философ еврейского происхождения, теолог, веривший во взаимное обогащение между двумя религиями христианством и иудаизмом, является одним из первых философов, который рассмотрел понятие «диалог» и интерпретировал его в рамках индивидуальной концептуальной картины мира. Основное звено в научной деятельности М. Бубера занимает исследование уникальной природы и всеобъемлемости диалога, раскрывающее извечные аксиомы бытия человека с миром посредством взаимоотношения, сосуществования и наличествования. Согласно М. Буберу, «настоящий диалог - не обусловленный заранее во всех своих частях, но вполне спонтанный, где каждый обращается непосредственно к своему партнеру и вызывает его на непредсказуемый ответ» [9, с. 231]. Следовательно, для осуществления диалога необходимо участие обоих партнеров, взаимность которых реализуется в рамках их внутренних и внешних характеристик. Эти отношения М. Бубер называет «диалогическими» $[15$, с. 65]. Диалогические отношения как результат обмена знанием между обоими партнерами закрепляется на предметном или духовном уровне и представляет собой взаимодействие через различные формы бытия.

В рамках исследования М. Бубер эксплицирует два диалогических подхода: первый, названный «первичной установкой на расстоянии» («Я-Оно»), второй «устанавливает отношения» («Я-Ты») [13, с. 86]. Первый подход является предпосылкой для второго, в котором человек может установить подлинный диалог «Я» и «Ты», только вступив в связь с установленным на расстоянии от нас бытием через мир «Оно». Второй подход представляет истинный диалог, проникну- 
тый любовью, в котором «Я» становится частью «Ты», однако «Ты» может трансформироваться в «Оно» под воздействием внешних и внутренних особенностей «Я». Другими словами, партнеры двух типов диалогического подхода тесно связаны между собой, дополняют и реализуются посредством друг друга, тем самым демонстрируют двойственную природу диалога. По словам М. Бубера, «мир двойствен для человека в силу двойственности его соотнесения с ним» $[9$, с. 7], поэтому диалогичность является основной константой в установлении отношений между человеком и миром, благодаря которым формируются культурные явления и прослеживается динамика прогресса.

Основные идеи диалога Мартина Бубера в полной мере отражены в его знаменитой книге «Я и Ты» (1922), в которой конструктивно подобраны и изложены фундаментальные установки отношений «Я-Ты» и «Я-Оно», проникнутые теологическими идеями М. Бубера как духовного наставника и философскими мыслями как экзистенциалиста. Первым подходом в реализации диалога является взаимодействие «Я-Оно», поскольку «Оно», «окруженное множеством «содержаний» $[9$, с. 5], осуществляется посредством вещей и предметов, которые обладают «прошлым» и избавлены от «настоящего», и тем самым взаимодействуют с «Я» на уровне обыденного сознания, которое ограничено пространством и временем как физической составляющей подобного диалога. «Оно» в отношении «Я-Оно» в любом случае может быть как он, она, животное, вещь, дух или даже Бог, которые выступают в качестве объекта, а «Я» - субъект. Следовательно, в рамках осуществления диалога «Я-Оно» следует обращать внимание на предметность «Оно» как на знание, которое в рамках предметного мира можно использовать и познать. Обмен происходит внутри человека, а не между ним и миром. Отсюда следует, что данные отношения всецело субъективны и лишены взаимности. Субъективность и информативность - главные особенности мира «Оно», которые также необходимы «Я» для осуществления диалога с «Ты». Человек на протяжении всей своей жизни ищет ответ, который связывает «Ты» с миром «Оно», потому что благодаря этому отклику создаются знание, действие, образы и символы, а также благодаря этому мир «Оно» перерождается в «Ты».

В данном случае диалог «Я-Оно» трансформируется в отношение «Я-Ты». «Отношение к «Ты» не опосредовано» [9, с. 4], между «Я-Ты» нет предшествующих элементов, связывающих их на предметном уровне, а вследствии этого понятия «пространство» и «время» утрачивают свою значимость. В отличие от объектно-субъективного знания в подходе «Я-Оно», знание отношений «Я-Ты» осуществляется на уровне «между» - во взаимном отношении полноценных и активных существ, где пространство и время утрачивают свое значение, поскольку «Я» вступает в отношения с «Ты» благодаря собственному духу, а не физическим составляющим компонентам. В данном случае «Ты» по отношению к «Я» выступает в качестве путника, визави, который «встречает меня по милости - его не обрести в поиске» $[9$, с. 4]. Ты в «Я-Ты» не ограничен человеческими отношениями, включает животных, деревьев, объектов природы и Бога. В рамках диалогических отношений «Ты», отождествляясь с «Оно», может принимать любую форму для осуществления диалога с «Я», но при этом существенные компоненты двух типов диалога диаметрально противоположны друг другу.

Отношения «Я-Ты» и «Я-Оно» обычно смешиваются друг с другом, поскольку «ни один человек не состоит из чистой сущности» [14, с. 36]. В соответствии с вышеуказанным положением «чистого» диалога не существует. 
В рамках диалогического подхода «Я-Оно» знание объектов является основным элементом в осуществлении диалога, что же касается диалогических отношений «Я-Ты», основными движущими силами в создании отношения «Я-Ты» являются духовные сущности, проживающие в настоящем, так как «настоящее возникает только через длящееся присутствие «Ты» [9, с. 10], а также через любовь между «Я» и «Ты».

В соответствии с философской концепцией диалога М. Бубера существует три важнейшие сферы, на которых строится мир отношений: «жизнь с природой», «жизнь с людьми», «жизнь с духовными сущностями» [9, с. 39]. Отличительная черта, характеризующая жизнь с природой, заключается в отсутствии речевой коммуникации. Диалог проходит на «немом» уровне, который реализуется в отношении человек - природа. Вторая сфера, на которой базируется мир отношений, это сфера личностных отношений между индивидами, где «отношение открыто, и оно оформлено в речи» [9, с. 3], реализуется в диалоге человек - человек. Оформленная в речь знаковая система — язык представляет основу для реализации данных отношений. Согласно высказыванию М. Н. Фоминой, «язык хранит не только память веков, но и обращенность к партнеру по диалогу» [11, с. 180], следовательно язык играет важную роль в создании диалога между человеком и человеком, который накапливает опыт культурной памяти и объекты культурного наследия. В рамках понимания третьей сферы отношение завуалировано, скрыто и сакрально, оно «не обладает речью, однако порождает ее» [8, с. 3]. Хотя мы «не слышим Ты» на физическом уровне, однако на ментальном или духовном уровне чувствуем и ощущаем голос зовущего нас. Данное отношение формируется на уровне «человек - Бог». Третья сфера «жизнь с духовными сущностями» или отношение «человек - Бог» занимает основное место в работах М. Бубера по исследованию диалога. Диалог М. Бубера пронизан религиознотеологическим содержанием, включающим учение хасидизма и христианства, которое воплотилось в «подлинном диалоге» [12, с. 43], согласно которому Бог существует в каждой вещи, Он трансцендентен, а не имманентен.

Одним из известнейших отечественных философов, исследователей диалога является Михаил Михайлович Бахтин (1895-1975), который внес огромный вклад в развитие теории диалога, первым предложил концепцию диалога культур, а также рассмотрел особенности диалога в культурном контексте на примере литературных текстов. Большое влияние на развитие диалогической мысли М. М. Бахтина оказали идеи М. Бубера. Работы М. М. Бахтина «Проблемы поэтики Достоевского» (1929), «Эстетика словесного творчества» (1979), «Творчество Франсуа Рабле и народная культура средневековья и Ренессанса» (1965) оказали колоссальное влияние на развитие диалогической мысли на последователей философии М. М. Бахтина и подняли диалог на новый уровень.

Основные идеи философской концепции диалога М. М. Бахтина неразрывно связаны с его исследовательской деятельностью, направленной на анализ литературного текста как составляющей диалога. Ядро развития диалогической мысли заключается в обращении к проблеме текста как атома общения личностей в диалоге через особый метод реализации диалога - понимание. Проблема исследования текста представляет основной костяк развития идеи диалога в творчестве М. М. Бахтина, согласно которой текст рассматривается как знаковая система, способствующая образованию диалога культур. Другими словами, каждый текст представляет в некоторой степени отражение предшествующих и последу- 
ющих ему текстов, созданных авторами, которые вложили личное мировосприятие картины мира в свое творчество, включающее смысл прошлых и последующих культур. Следовательно, текст всегда диалогичен, направлен на адресата и на выявление им индивидуального понимания. «Увидеть и понять автора произведения - значит увидеть и понять другое, чужое сознание и его мир, то есть другой субъект» [4, с. 306]. Как указано выше, в произведении личное мировосприятие автора может быть принято и осознано только посредством наличия адресата, через создание диалогических отношений. Опираясь на высказывание М. М. Бахтина о том, что «диалогические отношения - это почти универсальное явление, пронизывающее всю человеческую речь и все отношения, и проявления человеческой жизни...» [3, с. 71], можно сказать о многоаспектности диалогических отношений, которые реализуются во многих сферах жизни, в частности в контексте культур. Когда личность входит в диалогические отношения, творит мир понимающего и самоутверждающего духа, она создает культуру. В данном значении культура для человека выступает в качестве определяющего фактора в становлении индивида как личности. Однако в контексте культур это может быть реализовано лишь в диалогическом русле через диалог как всеобщую основу человеческого взаимопонимания и диалог как всеобщую основу всех речевых жанров. Согласно высказыванию С. С. Аверинцева, «жанр - это представитель культурно-исторической памяти в процессе всей идеологической деятельности... (летописи, хроники, научные тексты, похвала и т. д.)» [1, с. 102], следовательно благодаря жанру создается культурная память, а тексту — диалог культур, который представляет диалогическую встречу двух субъектов, погруженных в бесконечный культурный контекст. К тому же, субъектом встречи также выступает культура как самодетерминация самой себя. По словам М. М. Бахтина, «чужая культура только в глазах другой культуры раскрывает себя полней и глубже» [4, с. 334-335]. В результате встречи и соприкосновения двух культур один смысл выявляет свои особенности через призму другого смысла, и тем самым в момент встречи начинается диалог, который преодолевает камни преткновения в самодетерминации двух смыслов, двух культур.

В соответствии с вышеизложенным можно утверждать, что текст является источником порождения диалога культур, а понимание есть метод осуществления диалога, который направлен на адресата, на Другого, следовательно понимание выступает мостом в реализации отношений «я-для-себя», «я-для-другого» и «другой-для-меня». М. М. Бахтин предполагает двойную разновидность существования «Я»: с одной стороны, «Я» - обыденное, простое, «созерцающий субъект», с другой стороны, «Я»- ценное, объективное, Другой, с помощью которого осуществляется диалог с «Я». «Я» как субъект никогда не совпадает с самим собой: «Я» - субъект акта самосознания — выходит за пределы содержания этого акта [2, с. 132]. Согласно М. М. Бахтину, «Я» субъективен, не может стать объектом для себя и, как результат, не в силах познать и осознать сам себя. Человек как обыденное «Я» не способен в полной мере стать целостным для познания самого себя, поэтому только Другой в состоянии постигнуть и разобрать в подлинных смыслах настоящее «Я». «Другой может познать меня, а я могу познать Другого» [10, с. 13]. Таким образом, «Я» всегда направлено на Другого, направлено на диалог с ним, на осуществление диалогических отношений.

Работа по диалогу культур, проделанная М. М. Бахтиным, оказала огромное влияние на развитие философских идей Владимира Соломоновича Библера 
(1918-2000) - философа, культуролога, историка. Он взял за основу понятийную схему М. М. Бахтина о диалоге и выстроил методологическую базу для научного исследования диалога культур. В. С. Библер использует основные элементы диалога культур - текст и понимание, рассматривает их более детально и подробно. В. С. Библер, соглашаясь с М. М. Бахтиным, утверждает, что «бытие в культуре, общение в культуре есть общение и бытие на основе произведения, в идее произведения〉 [5, с. 115]. В дополнение к этому, В. С. Библер рассматривает текст, понимаемый как произведение, которое «живет контекстами, все его содержание только в нем, и все его содержание - вне его, только на его границах, в его небытии как текста» [6, с. 76]. Следовательно, интерпретация и понимание текста всецело зависят от контекста. Помимо этого, В. С. Библер выявляет несколько форм понимания, которые возникают при чтении текста: 1) восприятие текста; 2) узнавание и понимание значения в данном языке; 3) узнавание и понимание в контексте данной культуры; 4) активное диалогическое понимание [5, с. 76-78]. Тем самым он дополняет «понимание» М. М. Бахтина и подробно освещает внутренние особенности и компоненты концепции «понимания».

В соответствии с диалоговой теорией культур В. С. Библер акцентирует внимание на том, что индивид как личность в процессе своего становления всегда стремится к самодетерминации человеческого «Я», а также самодерминации мышления, сознания и судьбы. Как пишет В. С. Библер, «культура - это всеобщая история и деятельность человека, сосредоточенная в вершине самодетерминации» [6, с. 25], следовательно процесс самодетерминации является ключевым аспектом в создании культуры. Поэтому неслучайно, что в рамках созданной школы диалога культур В. С. Библер выдвигает идею о диалоге коренных образов личности в индивиде. К примеру, каждый возраст (ребенок, подросток, юноша) не растворяется в ходе последующего развития, не заменяется другим возрастом, а наслаивается, уплотняется в ходе развития собственных аргументов и потенций. В полноценном сознании взрослого на правах самостоятельных диалогических голосов присутствует и сознание дошкольника, и подростка, и юноши. Кроме того, В. С. Библер, рассматривая диалог культур, всецело охватывает и внедряет в исследование такие понятия, как мышление и сознание. Для него сознание есть событие себе «тождественных, вненаходимых «Я» и «Я», «Я» и предметного мира» [5, с. 211]. Поэтому сознавать - значит определять всем своим бытием бытие предмета и бытие человека. Сопряжение внутреннего общения с внешними общениями, называемое сознанием, является движущей силой для самодетерминации личности в создании культуры. Однако сознание не может существовать в единой проекции, сознание всегда ориентировано на мышление. По мнению В. С. Библера, «мышление есть то бытие, которое определяет неделимость сознания и несводимость его к отдельным психическим феноменам» $[5$, с. 65]. Сказанное позволяет заключить, что сознание и мышление являются одноуровневыми константами в осуществлении диалога личности в культурном контексте.

Помимо этого, В. С. Библер уделяет особое внимание логике в развитии своей философской концепции диалога, расширяя понятие «диалог» посредством ее внедрения как основополагающего элемента. Это позволяет ему разрабатывать понятие «диалогика», взяв за основу философские идеи диалектики через интерпретацию логики Гегеля. Таким образом, «диалогика» представляет собой «логику диалога логик», в которой «логики, ранее вступавшие и координирован- 
ные последовательно, поступательно, в XX веке проясняются в их одновременном общении, в диалогике самостоятельных Разумов» [5, с. 9]. В. С. Библер рассматривал два взаимодействующих разума - познающий разум и разум диалогический, и их момент «трандукции», в котором происходит переход познающего разума как самостоятельного собеседника в диалоге культур в разум диалогический.

В своей работе В. С. Библер придает особое значение логике культуры, в которой логика рассматривается как «диалогическое столкновение двух радикально различных культур мышления», которая образует единую логику — диалог логик» [5, с. 47]. Логика занимает важное место в развитии исследовательской деятельности диалога В. С. Библера, а именно, диалога «Я» и «Ты», «умозрения с опытом как диалог с самим собой» и «монолог одинокого мыслителя с самим собой, «Я» с «Ты» [5, с. 54]. Диалог с самим собой имеет место быть только в том случае, если обладает логической завершенностью, а именно выступает в тандеме «Я» знающее и «Я» незнающее, «Я» понимающее и «Я» непонимающее.

В. С. Библер акцентирует свое внимание на понятиях «диалог» и «диалогичность» как на неотъемлемых элементах внутреннего содержания личности. К примеру, логическая форма творческого мышления есть «форма внутреннего спора: «Я» утверждаю нечто. «Я» отвергаю это нечто, выдвигаю другое предложение» [5, с. 80]. В данном случае диалог есть внутренний спор с самим собой, «внутриинтеллектуальная игра рассудка, разума, интуиции», который актуализируется посредством мышления.

В рамках анализа логики культур В. С. Библер эксплицирует четыре типа диалогических включений: 1) «диалог интеллектуальных способностей (рассудок - разум - интуиция)», внутренний диалог, реализуемый в тандеме с интеллектуальными действиями; 2) «диалог теоретика», а именно диалог в собственном философском мышлении, созданный на основе научных теорий и исторических констант; 3) «диалог между теоретическим и эстетическим разумом», созданный в рамках творческого мышления и внутреннего спора между самим собой; 4) «диалог различных логических культур», в котором анализируется культура мышления Нового времени и классического разума [5, с. 117]. Диалог В. С. Библера имеет корни не только узкого диалогического направления, заключенного в постижении личности как самой себя, реализуемого на уровне «Я» и «Ты» посредством онтологического аспекта, творческих стимуляторов и внутреннего спора. Он акцентирует свое внимание на диалоге общем, диалоге культур и диалоге логик, в рамках которых анализируются культуры разных временных периодов и с помощью которых диалог В. С. Библера всецело проникается логикой как основополагающей единицей в диалогическом развитии.

На основе вышесказанного следует заключить, что формирование философской концепции диалога на сегодняшний момент является продуктом реализации трех видных мыслителей нашей эпохи: М. Бубер - М. М. Бахтин - В. С. Библер. Мартин Бубер вывел диалог за рамки антропологически ориентированных исследований, а также детально проследил понятийную структуру диалога. М. Бубер в первую очередь как теолог рассмотрел диалог в рамках философскорелигиозного аспекта, уделял большое внимание «Ты», а именно духовному «Ты» - Богу, в котором видел помощника в их внутреннем диалоге. М. М. Бахтин, опираясь на исследовательскую деятельность М. Бубера, рассмотрел диалог на основе литературных произведений через призму текста и его понимания, при 
этом одновременно эксплицировал концепцию диалога культур. В. С. Библер, используя концепцию диалога культур М. М. Бахтина, расширил границы понимания произведения и понимания текста в культурном контексте, а также рассмотрел диалог культур не только в философском аспекте, но и педагогической и психологической областях.

Литература

1. М. М. Бахтин как философ: сб. статей / С. С. Аверинцев [и др.]; Рос. академия наук, Институт философии. М.: Наука, 1992. 176 с.

2. Бахтин М. М. Автор и герой: к философским основам гуманитарных наук. СПб.: Азбука, 2000. $336 \mathrm{c}$.

3. Бахтин М. М. Проблемы поэтики Достоевского. 3-е изд. М.: Художественная литература, $1972.471 \mathrm{c}$.

4. Бахтин М. М. Эстетика словесного творчества. 2-е изд. М.: Искусство, 1986. 445 с.

5. Библер В. С. От наукоучения к логике культуры: два философских введения в двадцать первый век. М.: Политиздат, 1991. 413 с.

6. Библер В. С. Михаил Михайлович Бахтин, или Поэтика и культура. М.: Прогресс, $1991.176 \mathrm{c}$.

7. Библер В. С. Школа диалога культур: Идеи. Опыт. Проблемы. Кемерово: АЛЕФ, 1993. $416 \mathrm{c}$

8. Бубер М. Два образа веры. М.: Республика, 1995. 464 с.

9. Бубер М. Я и Ты. М.: Высшая школа, 1993. 175 с.

10. Зиновьева Н. Н. Проблема «Другого» в философии М. М. Бахтина // Известия Тульского государственного университета. Гуманитарные науки. 2011. № 1. С. 13-22.

11. Фомина М. Н. «Вечные проблемы» философского диалога // Вестник Читинского государственного университета (Вестник ЧитГУ). 2009. № 6. С. 178-182.

12. Anderson, Rob and Kenneth N. Cissna. The Martin Buber-Carl Rogers Dialogue: A New Transcript With Commentary. Albany: State University of New York Press, 1997. 138 p.

13. Buber M. I and Thou / Trans. Walter Kaufmann. N. Y.: Simon and Schuster, 1996. $185 \mathrm{p}$.

14. Buber, M. Between Man and Man / Trans. Ronald Gregor-Smith. N. Y.: Routledge, 2002. 67 p.

15. Friedman, Maurice S. Martin Buber: The life of dialogue / By Maurice S. Friedman. L.: Routledge a. Kegan Paul, 1955. X. 310 p.

\title{
TOWARDS THE PHILOSOPHICAL CONCEPT OF DIALOGUE (FROM MARTIN BUBER TO VLADIMIR S. BIBLER)
}

\author{
Tatyana O. Koryagina \\ Research Assistant, \\ Transbaikal State University \\ 30 Aleksandro-Zavodskaya St., Chita 672000, Russia \\ E-mail: kitay_koriagina@bk.ru
}

The article considers a dialogue as a philosophical concept with a number of characteristics and specific features. Dialogue as the basic form of a written or spoken conversational exchange between two or more people is transformed into a cultural dialogue, which is at the forefront of the dialogical relationship of a person with diverse forms of being. The research focuses on the interpretation of the concept of dialogue in the ideas of prominent thinkers such as M. Buber, M. M. Bakhtin and V. S. Bibler. Appealing to the scientific works of the above researchers, we explicate the distinguishing features of the dialogue. 
The main feature of a dialogue is its focus on the exchange of knowledge between two or more partners, whose relations are confirmed on objective or spiritual level. In accordance with the applied methods of scientific research (historical analysis and conceptual analysis), we have investigated the concept of dialogue and dialogical relations "I-Thou" and "IIt" (M. Buber), "I" and the Other (M. M. Bakhtin) and "I-You" (V. S. Bibler), as well as the dialogue of cultures in researches of M. M. Bakhtin and V. S. Bibler. The results of our investigation represent a theoretical background for the conceptual features of dialogue within the framework of philosophical tradition. The materials obtained can serve as a foundation for further research and analysis of the specific features and key principles of dialogism.

Keywords: dialogue; «I-Thou», «I-It», «I» and the Other; dialogue of cultures; dialogic relations; dialogics. 